\title{
Social inequalities and access to health: challenges for society and the nursing field
}

\author{
Regina Celia Fiorati ${ }^{1}$ \\ Ricardo Alexandre Arcêncio² \\ Larissa Barros de Souza ${ }^{3}$
}

Objective: to present a critical reflection upon the current and different interpretative models of the Social Determinants of Health and inequalities hindering access and the right to health. Method: theoretical study using critical hermeneutics to acquire reconstructive understanding based on a dialectical relationship between the explanation and understanding of interpretative models of the social determinants of health and inequalities. Results: interpretative models concerning the topic under study are classified. Three generations of interpretative models of the social determinants of health were identified and historically contextualized. The third and current generation presents a historical synthesis of the previous generations, including: neomaterialist theory, psychosocial theory, the theory of social capital, cultural-behavioral theory and the life course theory. Conclusion: From dialectical reflection and social criticism emerge a discussion concerning the complementarity of the models of the social determinants of health and the need for a more comprehensive conception of the determinants to guide inter-sector actions to eradicate inequalities that hinder access to health.

Descriptors: Social Inequity; Social Conditions; Public Health; Hermeneutics; Nursing.

\footnotetext{
${ }_{1}^{1}$ PhD, Professor, Faculdade de Medicina de Ribeirão Preto, Universidade de São Paulo, Ribeirão Preto, SP, Brazil.

2 PhD, Associate Professor, Escola de Enfermagem de Ribeirão Preto, Universidade de São Paulo, PAHO/WHO Collaborating Centre for Nursing Research Development, Ribeirão Preto, SP, Brazil.

${ }^{3}$ Master's student, Escola de Enfermagem de Ribeirão Preto, Universidade de São Paulo, PAHO/WHO Collaborating Centre for Nursing Research Development, Ribeirão Preto, SP, Brazil.
}

Fiorati RC, Arcêncio RA, Souza LB. Fiorati RC, Arcêncio RA, Souza LB. Social inequalities and access to health: challenges for society and the nursing field Rev. Latino-Am. Enfermagem. 2016;24:e2687. [Access ]; Available in: DOI: http://dx.doi.org/ 10.1590/1518-8345.0945.2687 


\section{Introduction}

Social determinants of health, such as social, economic, cultural, ethnic/racial, psychological, and behavioral factors, influence the occurrence of health problems and risk factors in the population have been marked by social and health inequalities found in peripheral urban areas, and geographical and cultural locations distant from the urban centers of large and medium-sized cities in Brazil(1).

The persistence of groups experiencing social exclusion and poverty in certain areas raises rates of social vulnerability, leading to exclusion or hindrance of access of people and groups to public services and devices, to tangible and intangible assets, and to opportunities that enable people to produce life with dignity. Exclusion or difficult access to health, income, work, education, housing, transportation or mobility, culture, leisure, a sustainable environment, and social support networks maintain health inequalities in these areas; that is, they mean that groups continue experiencing health problems and avoidable, unfair and unnecessary deaths ${ }^{(2)}$.

Studies show increased rates of social vulnerability among people and groups who often become vulnerable to poor environment, violence and certain diseases, with social determinants that may result in early death(3-7).

Therefore, this study's aim was to critically reflect upon the different interpretative models of the Social Determinants of Health (SDH) and inequalities that hinder the access and rights of people to health and the challenges imposed on healthcare providers, especially nurses, while designing actions intended to fight inequality, injustice, and unequal access to health among social segments subjected to social vulnerability and extreme poverty.

\section{Method}

This is a theoretical study, the theoretical framework of which is Habermas' critical hermeneutics, which seeks reconstructive understanding based on a dialectical relationship between the explanation and understanding of the phenomenon under study ${ }^{(8)}$.

Through an interpretative process and historicalcultural contextualization, we seek to increase understanding of this topic, combining interpretation and meaning based on an approach supported on the inter-subjectivity of a dialogical relationship between distinct, though symmetrical, semantic fields of interpreted material and interpretation ${ }^{(9-10)}$.
A bibliographical survey covering the last five years was conducted in the PubMed database to collect and select the material to be studied using the following descriptors: social determinants of health models, and social inequities in health. The search for the first descriptor resulted in 841 papers. After analyzing the abstracts and titles, only the studies that specifically addressed DSH models (37 papers) were selected. The search concerning the second descriptor resulted in 43 papers, but after the same analysis, none of them remained because they were empirical studies addressing specific populations and did not report the model or theoretical framework used.

The authors cited in the 37 papers that described or addressed Models of the Social Determinants of Health as being the references for the models mentioned were searched, namely: Margareth Whitehead, John W. Linch, Michael Marmot, Johan P. Mackenbach, Richard G. Wilkinson, Ichiro Kawachi/Lisa F. Berkman, and David Blane. Some documents were the basis of the historical constitution of the models: Commission on Social Determinants of Health - WHO - 2005; Comissão Nacional sobre Determinantes Sociais de Saúde [National Commission on Social Determinants of Health] - 2006 - Brazil, and The World Conference on Social Determinants of Health - 2011 - Rio de Janeiro, Brazil(11).

Therefore, a hermeneutic understanding of the texts and the models that concerned the object under investigation was sought considering four constituent areas of a hermeneutic analysis: historical and cultural context; the reconstructive understanding of intelligibility; dialectical understanding of context; and the production of social critical reflection.

According to the first constituent area, the social context in which the models were produced was contextualized in historical and cultural terms. Secondly, the empirical material was read aiming to acquire a reconstructive understanding of intelligibility different from what is intended with a given conception of reality.

In the third constituent area, a dialectical understanding is acquired of the context, in which circulate the various conceptions imbued in the studied models and the sociocultural whole in which these models are produced, so that an overview resulted from a whole indistinctly formed by its constitutive parts.

Finally, critical social reflection was possible with a view to critically update current conceptions presented in the SDH models and inequities in health were proposed with the goal to transform them, in order also to produce reflective knowledge, aiming 
to establish emancipatory social actions to overcome social inequalities.

\section{Results}

The material selected for this study was composed of the following authors cited in the 37 initial studies: 4 papers by Margareth Whitehead, whose model influenced the documents from the Commission on Social Determinants of Health - WHO - 2005 and of the Comissão Nacional sobre Determinantes Sociais de Saúde [National Commission on Social Determinants of Health] - 2006 - Brazil; 3 papers by Johan P. Mackenbach, which influenced the first analyses, strongly supported on socioeconomic differences as the primary determinants of health; 4 papers by John W. Linch, which influenced the neo-materialist models; 1 paper by Michael Marmot and 1 by Richard G. Wilkinson, whose studies generated the psychosocial approach to $\mathrm{SDH} ; 1$ paper by Ichiro Kawachi and Lisa F. Berkman, authors who addressed the social capital theory as a SDH; and 2 papers by David Blane, who studied the life course theory as a social determinant of life.

Hence, the studies were grouped into different models that were historically organized and are represented by three generations, according to Figure 1.

$1^{\text {st }}$ group - Description of the relationships between poverty and health

$2^{\text {nd }}$ group - Description of the health gradients according to various criteria of socioeconomic stratification

$3^{\text {rd }}$ and current group - Studies addressing how the mechanisms that produce inequalities and social injustice affect human health

Figure 1 - Generations of interpretative models of the Social Determinants of Health

The first group represents one generation of pioneering studies that showed that there is an intrinsic relationship between the way a society is organized and developed and the health of its population. This generation results from a tension in the field of public health between the dominant conception of biological-medical reference and other sociopolitical and environmental approaches in the determination of the health/disease continuum. The Alma-Ata Conference at the end of the 1970s, which highlights the social determinants of health, also influenced the development of the first studies.

The second generation of studies was developed in the 1980s and 1990s and is at the root of current research and models. Works by Margareth Whitehead, which stratifies the social determinants from those at the individual level up to those that interfere at the macro level, gain attention in this phase. The organization of the Commission of Social Determinants of Health by the World Health of Organization at the beginning of the 2000s is also highlighted.

The third generation includes current studies and interpretative models of $\mathrm{SDH}$, such as neo-materialist theories, psychosocial theories, theories of networks and social capital, the cultural-behavioral approach of epidemiology, and life course theory.

The neo-materialist approaches emphasize economic, political and social aspects as determinants of the production of health and disease, assuming that differences in income and access to goods and services influence health due to a scarcity of resources and an absence of investment in community infrastructure (e.g., education, transport, sanitation, housing, health services, etc.).

The psychosocial theories explore the relationships among perceptions of social inequalities, psychobiological mechanisms and health conditions based on the concept that the perceptions and experiences of people in unequal societies lead to stress and harm one's health.

Another model, social capital theory, seeks to analyze the relationships among the health of populations, unequal life conditions, and the level of development of the network of ties and associations between individuals and groups. Studies in this model identify the wear of the so-called "social capital", that is, solidarity and trust relationships between people and groups as an important mechanism, through which inequities of income negatively impact health.

The epidemiological cultural-behavioral approach makes an association between lifestyles that are individually adopted and their interface with culture and inequalities in the health field.

Finally, the life course theory defends the view that health and disease are a process that results from multiple inequalities and inequities that take place over the course of life of an individual in his/her social group. 


\section{Discussion}

Based on the historical-cultural contextualization of these models, discussion is focused on the third generation group, because the current interpretative models of SDH and social inequalities are those that encompass the models from previous generations and compose the framework that resulted from the contemporary historical process. That is, current models present a reconstructive synthesis of a theoretical-conceptual intelligibility that took shape based on an expanded conception of health, considered in a political and environmental context that interfaces with society and social relationships. The synthesis overcomes a paradigm that considered the health/ disease continuum only within biological boundaries.

In this sense, neo-materialist theories highlight that a scarcity of resources that negatively impacts health results from economic processes, mainly derived from inequalities concerning income, modes of production, appropriation of production means, working relationships, and also results from political decisions that produce immense social inequality, thus impeding people from living with dignity(12).

From a parallel perspective, psychosocial theories focus on the view that the perceptions of individuals in an unequal society, when occupying a disadvantageous social position and experiencing poor community reciprocity, experience stress and health disorders as a consequence. This conception, therefore, restricts the environmental and community determinants of health to psychological and biological mechanisms, disregarding other important social constraints ${ }^{(13)}$.

The social network and social capital model, based on the work of thinkers such as Robert Putnam, James Coleman, and Pierre Bourdieu, defines social capital as a specific form of social organization in which there is a strong network of interpersonal relationships grounded on reciprocity and social cooperation. This organization produces capital in the form of personal and collective development that determines development in all other sectors: economic, cultural, political, social as well as in the health field. Hence, the set of individual resources is transformed and enhanced based on social cohesion and collective resources, triggering both individual and collective benefits. Social capital, therefore, is defined as the social tissue or invisible glue that maintains the cohesion of societies and is based on trust among people and the network of relationship maintained among these people and social groups that form the community. According to this theory, inequalities are resolved based on the existence of a strong community foundation, with strong ties of reciprocity and solidarity ${ }^{(14-15)}$.

The cultural-behavioral conceptions that permeate the epidemiological approach mean that from the (more or less conflictive) relationships among individual choices (which result from people's selfdetermination and freedom), the interface of these choices with culture and its influence on the choices of individuals regarding certain lifestyles, a certain way of life results that influences and favors the health/ disease continuum of individuals and their groups of belonging(16).

The life course theory shows that events that characterize the lives of individuals from life inside the womb to childhood, adolescence and adulthood, influence the health of people and have cumulative effects that interact with successive circumstances that take place over the course of life and determine levels of health. Hence, when analyzing the course of life of an individual and his/her health, we verify that there are differences between someone born in a suburban context such as a slum and someone born in a middle class context ${ }^{(17)}$.

The current debate around SDH and inequalities reveal not only the potential of each model but also highlight their limitations.

Therefore, in the debate among the conceptions included in current models, criticism of the neomaterialist model refers to the one-sided emphasis given to economic factors linked to income and the material conditions of life. In regard to the psychosocial models, we note the limitation of narrowing the issue to merely organic and psychological manifestations generated by social inequality, not properly considering economic and political models that generate these social inequalities. The criticism of the theory of social capital raises the issue that this conception disregards inequalities in the distribution of political power, attributing extreme responsibility to civil society and, as a consequence, takes from the State the responsibility of providing social protection. The criticism concerning the cultural-behavioral theory falls on the one-dimensional vision focused on lifestyles while disregarding political-social factors. Finally, the life course theory is merely linked to geographically determined issues ${ }^{(1)}$.

The analysis seeking dialectical understanding of the context in which these theories are produced reveals that one theory is not an alternative to the other; that is, these theories are not contradictory or mutually exclusive. Rather, they complement each other as they reflect different contextualizations of the same, extremely complex, reality experienced 
by modern society. This social complexity results in multifaceted interpretations of reality, which based on cultural multidimensionality, generate polysemic interpretations of social reality.

This perspective reveals the importance of building interfaces among models and valuing ecosocial approaches and so-called multilevel approaches, which seek to integrate individual and group, social and biological, approaches from a dynamic, historical and ecological perspective ${ }^{(18)}$.

Comparing materialistic and non-materialistic models is not useful. The complexity of contemporary issues demands a comprehensive approach that encompasses structural determinants, that is, both political and socioeconomic contexts and related factors, such as income, labor, education, housing, organization of health systems, social policies, gender, and ethnicity, among other determinants. Intermediary determinants also need to be included, such as psychosocial, cultural and behavioral approaches, which unfold in factors related to living environment, belonging groups, social cohesion, and biological and genetic factors ${ }^{(19)}$.

We can organize the models of the social determinants of health into intersection groups looking for interfaces among structural and intermediary determinants to encompass an analysis of the sociopolitical and economic contexts and the cultural and biopsychosocial contexts in which social inequalities are generated. The structural determinants that generate social stratification include income, education, labor, social mobility, and housing factors, along with access to goods and services and political power, among others. The intermediary determinants arise from a configuration of subliminal social stratification and cause differences in terms of exposure and vulnerability to conditions that compromise health that is linked to cultural, psychosocial and behavioral factors, such as: gender, ethnicity, and sexuality, social networks of support and belonging, social cohesion, solidarity and social capital, in addition to living conditions, working conditions, availability of food, the population's behaviors, and barriers to adopting a healthy lifestyle.

Hence, social and political contexts are considered to be determinant factors that influence the health/ disease continuum in certain population segments and social contexts that include rapid urban growth, such as settlements and residential areas with poor sanitation and living conditions, the place where children are raised, which itself influences one's development over the entire course of life, working conditions and processes, the health system and access to public services. We also note, however, that all these factors are conditioned by the political macrodeterminant linked to the globalization of the economy and its effects on national economies that result in ways of political organization focused on economic development at the expense of social policies ${ }^{(20)}$.

Even if SDH equally included the way people, groups and populations work, their cultural manifestations and conceptions regarding health, disease and how diseases are treated, the unequal conditions in which many social segments are inserted, are in fact what have the most impact on and determine the most the persistence of diseases and conditions that could be eradicated. In other words, technology and knowledge exists to eradicate diseases but no effective result is achieved. As a consequence, a portion of the population lives in avoidable, unnecessary and unfair social vulnerability ${ }^{(1)}$.

A comprehensive analysis of the different models of SDH reveals that determinants are directly at the foundation of the production of social inequalities that negatively impact the health of people, groups and populations at different levels, even leading to death. Unequal living conditions are characterized by existential states that do not ensure a dignified life. Living with dignity can be defined as a situation in which people experience the minimum and sufficient conditions necessary to live with dignity, which are universal rights of all men, women and children: universal access to the social and collective reproduction of life, such as having a job, income, access to quality health services, education, culture, housing, transportation, leisure, a sustainable environment, and social solidarity and support networks. Hence, social inequalities can be defined as certain existential conditions under which there is unequal access, or even a lack of access, to human rights that ensure a minimum level of human dignity ${ }^{(21)}$.

It is worth noting, however, that when we consider this definition, social inequalities are by themselves unfair, unnecessary, and avoidable because they basically constitute a lack of access to minimum conditions that enable people to have a dignified life, and, therefore, these living conditions are unequal in their essence because they are not justifiable under any aspects, as they are inhumane. They are unnecessary and avoidable because these inequalities are imputed by other human agents in their social relationships, relationships marked by inequality of (economic, political or sociocultural) power rather than natural or technological agents (e.g., biological and/or lack of knowledge or technology to overcome diseases). 
Social inequalities are, therefore, socially determined needs that constrain the existence of people, groups and populations, which are characterized by unequal access or lack of access to tangible and intangible goods and human assets preventing people from having a dignified life and are a result of a violation of rights imputed by the actions of the State, government agencies and omission on the part of civil society(22).

From this point of view, what are the challenges posed to society? Based on the conclusion that social inequalities are unjustifiable from any perspective whatsoever, the challenge of constructing a fair and democratic community that is posed to society is immense. The practice of nurses should match these values. There is, therefore, an urgent need to establish universal access to goods and human assets and to ensure the unconditional respect of human rights.

The following human and collective assets and goods considered in this study include: socioeconomic assets such as education, health, labor and income, housing, sustainable environment, transportation and mobility, sport and leisure, among others. Cultural assets include: information at all levels, social manifestations and acknowledgment of values, beliefs, and specific systems of knowledge; acknowledgment of the social realizations of these specific systems of knowledge, and cultural manifestation and democratization of public spaces. Political assets include: power to deliberate over social, financial and political issues; being included in organized social forms of expression and the exercise of citizenship and decision-making. Social assets include: being included in civil society and public representation, social support networks (belonging to support groups and social cohesion, solidary relationships networks and social inclusion) $)^{(23)}$.

In this sense, the non-accessibility of people and groups to these goods and assets constitutes a violation of rights and occurs at three levels: by the action of the State - management of society based on a system of domination, legitimating unequal access to power, structures that distance deliberative bodies from society and that legitimate the prevalence of economic interests (market, capital) over dimensions of human existence based on ethical values. At a second level, it occurs by the political-social organization represented by the governmental spheres (segments that hold political power) and give privileges to economic corporations, maintain policies and legal instances that legitimate the concentration of wealth and power by blocking information and exerting violent domination over society and economic classes that rank lower in the social stratification. At a third level, it occurs by an omission on the part of civil society forms of popular organization based on any symbolic system that naturalizes social inequalities, which are characterized as social injustice, legitimating criteria based on ideology-based beliefs and prejudice that are culturally disseminated(22).

Considering how inequalities affect human health, we present a reality in which health systems, the quality of these services and access to them and to improved technologies in the health field. are unequally distributed among people and groups that compose society in this social and political-economic organization we know. Hence, groups and people whose rights are violated have no access (or only difficult access) to services, treatment and technology regarding the delivery of quality health.

The needs experienced by certain populations and socially vulnerable people lead them to experience even greater social and health needs. Lack of access to services and treatments and technology that enable quality health delivery negatively affect health, life and death in these social groups. In other words, these groups experiencing social vulnerability and whose rights are violated present greater needs as a results of the immense deficiency they experience. Hence, from this perspective, they should have greater access to services, treatments and technologies in the health field. However, this is not what happens in practice; there is a certain mismatch between the supply of actions and needs ${ }^{(2)}$.

Nurses, whose practices should be attuned to the demands and needs manifested in their territories, face many limitations, whether in terms of resources and technologies or due to their education, still strongly focused on "assistencialism"* and with restricted knowledge concerning the Political State of Rights. Therefore, theoretical studies are needed to verify the primary determinants of social inequality and their interfaces with health services and to recognize the challenges of the nursing field to imprint a logic of work from an emancipatory perspective with a view of the active role of communities(24).

\footnotetext{
* Assistencialism is a term used in Latin America associated with the idea of treating individuals as mere recipients of aid rather than active individuals capable of transforming their environment. Source: http:// www.chrusp.org/blog/entry/1186641/assistencialism-vs-liberation
} 
The arsenal currently available for healthcare providers is based on classical educational models, which, in addition to operating with technologies that are not sensitive to context, do not take into account the differences among communities. There seems to be only a single package of actions available for communities, regardless of their level of difficulties or needs. To overcome these challenges, however, the education of these professionals needs to provide an extended historical-social perspective ${ }^{(25)}$.

\section{Conclusion}

Stratifying a community in terms of its social risk and, therefore, taking into account its health needs, is essential to overcoming social inequalities in terms of access. New technologies are necessary to reveal the areas at a greater social disadvantage, as well as new knowledge needed to understand the roots of inequalities. The deeper the reflection upon inequalities and their interfaces with access, the more feasible and more achievable are the solutions.

Hence, the creation of inter-sector instances, beyond the health field, combining their resources to devise public policies are needed to solve unequal access to health and enable all people in our society and the global community to fully enjoy social rights. This is the great challenge for all of us in the $21^{\text {st }}$ century.

\section{References}

1. Arcaya MC, Arcaya AL, Subramanian SV. Inequalities in health: definitions, concepts and theories. Global Health Accion. 2015;8(27106):1-12.

2. Frenk J, Moon S. Governance challenges in global health. N Engl J Med. 2013;368(10):936-42.

3. Chaves TV, Sanches ZM, Ribeiro LA, Nappo SA. Fissura por crack: comportamentos e estratégias de controle de usuários e ex-usuários. Rev Saúde Pública. 2011;45(6):1168-75.

4. Reichenheim ME, Souza ER, Moraes CL, Mello Jorge MHP, Silva CMFP, Minayo MCS. Violence and injuries in Brazil: the effect, progress made, and challenges ahead. Lancet. 2011;377(9781):1962-75.

5. Gomes BR, Adorno RCF. Tornar-se "noia": trajetória e sofrimento social nos "usos de crack" no centro de São Paulo. Etnográfica. 2011;15(3):569-86.

6. Yamamura M, Santos Neto M, Freitas IM, Rodrigues LBB, Popolin MP, Uchoa SAC, et al. Tuberculose e iniquidade social em saúde: uma análise ecológica utilizando técnicas estatísticas multivariadas, SãoPaulo, Brasil. Rev Panam Salud Publica. 2014;35(4):270-7.
7. Fiorati RC, Carretta RYD, Kebbe LM, Xavier JJS, Lobato BC. Inequalities and social exclusion among homeless people: a Brazilian study. Am Int J Social Sci. 2014;3(6):5-14.

8. Taquette SR, Minayo MCS. The main characteristics of qualitative studies carried aut by doctors in Brazil. Cien Saúde Coletiva. 2015;20(8):2423-30.

9. Habermas J. Political communication in media society: does democracy still enjoy an epistemic dimension? The impact of Normative Theory on empirical research. Commun Theory. 2006;16(4):411-26.

10. Flajoliet $A$. L'Herméneutique à la Phénoménologie de I'ouvre littéraire. Estud Pesqui Psicol. 2008;8(2):309-33.

11. Pellegrini A Filho. Conferência Mundial sobre Determinantes Sociais de Saúde. Cad Saúde Pública. 2011;27(11):2080-2.

12. Maika A, Mittinty MN, Brinkman S, Harper S, Satriawan E, Lynch JW. Changes in socioeconomic inequality in Indonesian Children's Cognitive function from 2000 to 2007: a decomposition analisis. PLoS One. 2013;8(10):1-9

13. Marmot M. Global Accion on social determinants of health. Bull Wrld Health Organ. 2011;89(10):702.

14. Helal DH, Neves GAB. Superando a pobreza: o papel do capital social na região metropolitana de Belo Horizonte. Cad EBAPE.BR. 2007;5(2):113.

15. Aida J, Kondo K, Kondo N, Watt RG, Sheihan A, Tsakos G. Income inequality, social capital and dental status in older japanese. Soc Sci Med. 2011;73(10):1561-8. 16. Geib LTC. Determinantes Sociais da saúde do idoso. Ciênc Saúde Coletiva. 2012;17(1):123133.

17. Victora CG, Aquino EML, Leal MC, Monteiro CA, Barros FC, Szwarcwald CL. Maternal and Child health in Brazil: progress and challenges. Lancet. 2011;377(9780):1863-76

18. Almeida-Filho N. Higher education and health care in Brazil. Lancet. 2011;377(9781):1898-1900.

19. Buss PM, Magalhães DP, Setti AFF, Gallo E, Franco Netto FA, Machado JMH, et al. Saúde na Agenda de Desenvolvimento do pós-2015 das Nações Unidas. Cad Saúde Pública. 2014;30(12):2555-70.

20. Sapir A. Globalization and the reform of European social models. J Common Market Stud. 2006;44(2):369-90.

21. Starfield B. The hidden inequity in health care. Int J Equity Health. 2011;10(1):15.

22. Fleury S. Brazil's health-care reform: social movements and civil society. Lancet. 2011;377(9779):1724-5. 
23. Andrade LOM, Pellegrini A Filho, Solar O, Rígoli F, Salazar LM, Serrate PCF, et al. Social determinants of health, universal health coverage and sustainable development: case studies from Latin American countries. Lancet. 2015;385(9975):1343-51.

24. Nichiata LYI, Bertolizzi MR, Takashi RF, Fracolli LA. The use of "vulnerability" concept in the nursing area. Rev. Latino-Am. Enfermagem. 2008;16(5): 923-8.

25. Langdon EJ, Wiik FB. Anthropology, health and illness: an introduction to the concept of culture applied to the health sciences. Rev. Latino-Am. Enfermagem. $2010 ; 18(3): 459-66$.

Copyright @ 2016 Revista Latino-Americana de Enfermagem This is an Open Access article distributed under the terms of the Creative Commons (CC BY).

This license lets others distribute, remix, tweak, and build upon your work, even commercially, as long as they credit you for the original creation. This is the most accommodating of licenses offered. Recommended for maximum dissemination and use of licensed materials. 